July 2006

\title{
Endoscopic sphincterotomy with or without cholecystectomy for choledocholithiasis in high risk surgical patients: A decision analysis
}

\author{
Ali Siddiqui \\ Thomas Jefferson University \\ Pradnya Mitroo \\ Thomas Jefferson University \\ Thomas E. Kowalski \\ Thomas Jefferson University \\ David Loren \\ Thomas Jefferson University \\ Follow this and additional works at: https://jdc.jefferson.edu/medfp \\ Part of the Medical Genetics Commons \\ Let us know how access to this document benefits you
}

\section{Recommended Citation \\ Siddiqui, Ali; Mitroo, Pradnya; Kowalski, Thomas E.; and Loren, David, "Endoscopic sphincterotomy with or without cholecystectomy for choledocholithiasis in high risk surgical patients: A decision analysis" (2006). Department of Medicine Faculty Papers. Paper 21. https://jdc.jefferson.edu/medfp/21}

This Article is brought to you for free and open access by the Jefferson Digital Commons. The Jefferson Digital Commons is a service of Thomas Jefferson University's Center for Teaching and Learning (CTL). The Commons is a showcase for Jefferson books and journals, peer-reviewed scholarly publications, unique historical collections from the University archives, and teaching tools. The Jefferson Digital Commons allows researchers and interested readers anywhere in the world to learn about and keep up to date with Jefferson scholarship. This article has been accepted for inclusion in Department of Medicine Faculty Papers by an authorized administrator of the Jefferson Digital Commons. For more information, please contact: JeffersonDigitalCommons@jefferson.edu. 


\title{
Endoscopic sphincterotomy with or without cholecystectomy for choledocholithiasis in high-risk surgical patients: a decision analysis
}

\author{
A. SIDDIQUI, P. MITROO, T. KOWALSKI \& D. LOREN \\ Division of Gastroenterology and Hepatology, Thomas Jefferson University Hospital, \\ Philadelphia, PA, USA \\ Correspondence to: Dr A. A. Siddiqui, University of TexasSouthwestern Medical Center, 4500 \\ S.Lancaster Road (111B1), Dallas, TX75216, USA. E-mail:ali.siddiqui@utsouthwestern.edu
}

\begin{abstract}
Background

Laparoscopic cholecystectomy (LC) is recommended for patients with choledocholithiasis after ERCP with sphincterotomy (ES) and stone extraction.
\end{abstract}

Aim

We designed decision model to address whether ES alone versus ES followed by LC (ES + LC) is the optimal treatment in high-risk patients with choledocholithiasis.

\begin{abstract}
Methods
Our cohort were patients with obstructive jaundice who have undergone an ES with biliary clearance. Recurrent biliary complications over 2-year period stratified by gallbladder status (in/out) and age-stratified surgical complication rates were obtained from the literature. Failure of therapy was defined as either recurrent symptoms or death attributed to biliary complications.
\end{abstract}

\section{Results}

For age $70-79$ years, ES failed in 15\% whereas ES LC failed in $17 \%$ of cases. Mortality in the EC LC group was 3.4 times that of the ES alone cohort. For age 80+ years, ES was dominant with an incremental success rate of $8 \%$. Mortality in the ES LC was 7.6 times that of ES. For age $<70$, ES LC was the dominant strategy with an incremental success rate $5 \%$. Sensitivity analysis in the groups confirmed our conclusions.

\section{Conclusions}

Management of choledocholithiasis by ES and stone clearance, but without cholecystectomy, should be considered for patients aged 70+. For low-risk patients, ES LC should be performed to prevent recurrent biliary complications.

\section{INTRODUCTION}

Endoscopic retrograde cholangiopancreatography (ERCP) with endoscopic sphincterotomy (ES) is accepted as the therapy of choice for patients with stones in the bile duct. ${ }^{1-3}$ Endoscopic stone extraction is successful in over $96 \%$ of patients ${ }^{3-5}$ with a low procedure-related morbidity (5.8\%) and mortality $(0.2 \%)$.Subsequent laparoscopic cholecystectomy $(\mathrm{LC})$ is the standard treatment in those patients with concomitant gall-bladder stones. The rationale for

(C) 2006 The Authors. This is the authors' version prior to publication in Alimentary Pharmacology \& Therapeutics 24(7):1059-1066, October 2006. The definitive version is available at www.blackwell-synergy.com (http://dx.doi.org/10.1111/j.1365-2036.2006.03103.x) Journal compilation @ 2006 Blackwell Publishing. 
cholecystectomy is to prevent biliary complications such as acute cholecystitis, biliary colic, recurrent biliary stones, cholangitis and biliary pancreatitis. Many patients with biliary stones are elderly and have multiple comorbid conditions and are thus poor surgical candidates. Postoperative mortality and morbidity increase with age and associated comorbid diseases. ${ }^{6,7}$ Several groups have proposed that endoscopic extraction of bile duct stones, with the gall-bladder left in situ, could be an option in high surgical risk patients presenting with jaundice secondary to choledocholithiasis. ${ }^{8}$ Although endoscopic therapy may carry lower immediate morbidity or mortality, late biliary complications are not uncommon. The decision whether to proceed to surgery is further complicated by the fact that the morbidity and mortality of LC have declined with greater surgical

experience. ${ }^{9,10}$ Additionally, some of the studies that advocate use of ES in highrisk patients do not agree with the definition of high surgical risk. ${ }^{11,2}$ We designed decision analysis to address whether ES alone vs. ES followed by $\mathrm{LC}(\mathrm{ES}+\mathrm{LC})$ is the optimal treatment modality in high-risk patients with choledocholithiasis.

\section{PATIENTS AND METHODS}

\section{Literature review}

A Medline research looking at English language articles from 1990 to the present was performed for variation of the following terms: ERCP, ES, LC, elderly, gallstones, cholelithiasis, morbidity and mortality. Bibliographies of accepted articles were reviewed and we searched recent issues of peer-review journals of gastroenterology and surgery. Only studies that had more than 10 patients and outcome data that could be abstracted were used. Updated series took precedence over older studies from the same institution. Some variability was noted in the studies reporting testing characteristics and complications rates for the different variables. Weighted mean values for each parameter were calculated from the usable trials and applied to our decision tree. All probabilities for clinical inputs in the model, as well as the range tested in the sensitivity analysis, are summarized in Tables 1 and 2 .

\section{Decision analytical model}

Using a decision analysis software program, DATA 3.5 (TreeAge Software Inc., Williamstown, MA, USA), we evaluated the clinical outcomes and recurrent biliary complications in patients with cholelithiasis within 2-year period in three different age groups: (i) patients younger than 70 years. (ii) patients of age 70-79 years (base cohort). (iii) patients of age 80 years or more. The decision tree used in the analysis is illustrated in Figure 1.

For each of the age groups, the analysis started with cohort of 100 hypothetical patients with intact gallbladders presenting with obstructive jaundice because of

(c) 2006 The Authors. This is the authors' version prior to publication in Alimentary Pharmacology \& Therapeutics 24(7):1059-1066, October 2006. The definitive version is available at www.blackwell-synergy.com (http://dx.doi.org/10.1111/j.1365-2036.2006.03103.x) Journal compilation @ 2006 Blackwell Publishing. 
cholelithiasis. All patients underwent successful ERCP with ES and biliary clearance without complications. Patients were then assigned to two groups: group I $(E S+L C)$, in which patients were treated with $L C$ to remove the gallbladder following ES and group II (ES only), in which the gall-bladder was left in situ after ES.

Patients in group I underwent an ES followed by an LC. The decision model was divided into that subset of patients who had immediate complications following LC and those patients who had no surgical complications. In the group of patients who had immediate surgical complications, the mortality and morbidity of LC were modeled based on published rates in the literature. Those patients who did not die because of surgical complication nor had post-operative complications were then assessed for long-term recurrent biliary complications and mortality within 2-year period.

Patients in group II underwent an ES and the gallbladder was left in situ. These patients were then assessed for long-term recurrent biliary complications and mortality within 2-year period.

\section{Appraisal of clinical outcomes}

The decision tree was used to evaluate the preferred treatment strategy for management of choledocholithiasis in patients in each of the three different age groups. Short-term operative mortality and morbidity were assessed. Failure of therapy was defined as either recurrent symptoms or death attributed to biliary complication.

\section{Sensitivity analysis}

The performance characteristics were varied to determine the threshold patient age and complication rates that would alter treatment strategies using one-way and multiple-way sensitivity analyses so as to detect its effect on the ultimate results.

It is not realistic to rely upon one value for probabilities, as there is marked variability in outcomes seen in the literature. In doing sensitivity analysis, we can see whether changing the mortality and mortality rate alters the favored decision strategy. If it does not, this proves the robustness of the model. If it does alter the strategy, the model is considered to be sensitive to changes in the probability of that particular test. In the final analysis, this helps determine the most optimal treatment modality for patients with choledocholithiasis, who are at increased surgical risk.

One-way sensitivity analyses were done by varying single variable baseline probabilities over credible range and then interpreting their effect on final

(c) 2006 The Authors. This is the authors' version prior to publication in Alimentary Pharmacology \& Therapeutics 24(7):1059-1066, October 2006. The definitive version is available at www.blackwell-synergy.com (http://dx.doi.org/10.1111/j.1365-2036.2006.03103.x) Journal compilation (c) 2006 Blackwell Publishing. 
outcomes. For each scenario, one-way sensitivity analysis was performed, plotting success of therapy against surgical complications, to determine the optimal strategy to follow (ES + LC vs. ES alone). Three-way sensitivity analysis of recurrent complications in ES, ES LC and surgical morbidity was then performed to further validate the strength of the decision model.

\section{RESULTS}

\section{Decision tree analysis}

\section{Age less than 70 years}

In patients who were less than 70 years of age, the ES + LC was the dominant strategy. Patients with choledocholithiasis who underwent an ES followed by LC had a $90 \%$ overall success rate with 2-year mortality rate of 0.05 per 100 patients. In comparison, patients with choledocholithiasis who underwent only an ES had an $85 \%$ overall success rate. The ES-only group had 2 -year mortality rate of 0.1 per 100 patients, which was twice that of the ES + LC group. A oneway sensitivity analysis identified threshold surgical complication rate of $9.8 \%$ (Figure 2), above which ES was the dominant strategy and further validated that in patients less than 70 years of age with biliary obstruction because of choledocholithiasis, ES followed by LC should be the treatment of choice. Patients who underwent only ES had lower overall success rate and higher mortality.

\section{Age 70-79 years (base cohort)}

In patients aged 70-79 (base cohort), ES alone was the dominant strategy when compared with ES + LC. The ES-alone group had an overall success rate of $85 \%$ when compared with the ES + LC group that had an $83 \%$ success rate. The ESalone group thus has an incremental success rate of $2 \%$. The ES-alone group had $15 \%$ failure rate when compared with $17 \%$ in the ES + LC group. The 2-year mortality in the EC + LC group was 3.4 times that of the ES-alone cohort. Oneway sensitivity analysis determined threshold surgical complication rate of $10 \%$ (Figure 3), above which ES was the dominant strategy; therefore in patients of age 70-79 years with biliary obstruction because of choledocholithiasis, ES alone should be the treatment of choice. ES + LC have higher failure rates and mortality in this age group.

\section{Age 80 years and above}

For the cohort of age 80 years or more, ES was dominant with an overall success rate of $86 \%$ when compared with $78 \%$ in the ES + LC group. The ESonly group, therefore, had an incremental success rate of $8 \%$ over ES + LC. Three-way sensitivity analysis of recurrent complications in ES, ES + LC and

(c) 2006 The Authors. This is the authors' version prior to publication in Alimentary Pharmacology \& Therapeutics 24(7):1059-1066, October 2006. The definitive version is available at www.blackwell-synergy.com (http://dx.doi.org/10.1111/j.1365-2036.2006.03103.x) Journal compilation (c) 2006 Blackwell Publishing. 
surgical morbidity, identified ES as the dominant strategy in all cases except when biliary complications for ES

exceeded $22.2 \%$ (range $6-24 \%$ ). Mortality in the ES + LC group was 7.6 times that of the ES cohort. ES-alone group had an overall greater success rate and lower mortality rate compared with the ES + LC group.

The decision analysis results are summarized in Table 3.

\section{DISCUSSION}

We constructed a decision analysis, attempting to simulate the clinical scenario of patient presenting with obstructive jaundice because of an obstructed common bile duct stone. Patients were stratified into three different age groups, and the model was used to determine the optimal management strategy. We found that ERCP with sphincterotomy (ES) and stone clearance, but without cholecystectomy, should be strongly considered for patients aged 70-79 (base cohort). In patients of age 80 years and above, ERCP with ES alone was the dominant strategy, largely because of increased surgical complication rates. For low-risk patients (less than 70 years of age), ES followed by LC should be performed to prevent recurrent biliary complications and decrease overall morbidity and mortality.

Decision modeling uses complex clinical situation and is based on previously published data. It helps serve as an adjunct to clinical decision making. It should be remembered that decision modeling is subject to several limitations. The influences of factors such as patient preferences that may impact the choice of clinical approach are difficult to access. Our decision model has several limitations. The model has level of uncertainty when looking at the clinical assumptions. Like all decision models, the limitations may affect the validity and generalizability of our findings. Therefore, sensitivity analysis allows us to address this uncertainty by giving range of values to inputs prone to uncertainty. We have made number of simplifying assumptions so as to create working decision model that may not capture many of the subtleties that happen in clinical practice.

Patients who present with obstructive jaundice secondary to bile duct stones usually undergo an ES followed by LC. Procedure complication rates from both elective and emergency ERCPs in the elderly are similar to those of the younger age groups, despite the geriatric population having more comorbidities. ${ }^{12,13} \mathrm{~A}$ study by Clarke et al. ${ }^{14}$ showed that post-ERCP pancreatitis occurred in $5 \%$ of patients aged 85 or above. This was similar rate to younger patients. ${ }^{13}$ Although it is well documented that patients undergoing endoscopy can experience hypoxaemia, it is not clear whether this contributes to any associated complications. ${ }^{15,16}$

(c) 2006 The Authors. This is the authors' version prior to publication in Alimentary Pharmacology \& Therapeutics 24(7):1059-1066, October 2006. The definitive version is available at www.blackwell-synergy.com (http://dx.doi.org/10.1111/j.1365-2036.2006.03103.x) Journal compilation (c) 2006 Blackwell Publishing. 
As opposed to endoscopy, there is an increase in incidence of post-operative mortality and morbidity after cholecystectomy with advancing age. The elderly are at an increased risk for surgery because of concurrent comorbidities, decreased functional reserve and greater chance that surgery will be done on an emergency basis. ${ }^{10}$ Several studies have looked at the results of LC in the elderly population. ${ }^{17-20}$ The majority of these studies are compromised of small number of patients, and there are only two reports that focused out outcomes in octogenarians. ${ }^{21,22}$ These studies have reported that when compared with younger patients, the elderly have more complications, higher rates of conversion to an open cholecystectomy, and longer post-operative hospitalization. Maxwell et al. ${ }^{22}$ compared 105 octogenarians to control group of 210 patients who were younger than 80 years. His study showed that patients older than 80 years required more emergency surgery (11\% vs. $4.8 \%$ ), had higher intra-operative complications (13\% vs. $3.3 \%)$ and greater incidence of conversion to an open cholecystectomy ( $16 \%$ vs. $8.6 \%$ ). The overall complication rate was also higher in octogenarians.

Elective cholecystectomy after ES is still arguable. Certain surgical reports suggest that the presence of cholelithiasis is an indication for elective cholecystectomy after ES. ${ }^{23}$ Surgical sphincterotomy has been shown to prevent gallstone formation in prairie dogs. ${ }^{24,25}$ In humans, ES stimulates gall-bladder motility and was thought to prevent further gallstone formation. ${ }^{26}$

Boerma et al. ${ }^{27}$ did prospective, randomized trial in 120 patients with gall-bladder stones, who underwent an ES for common bile duct stones. Patients were then randomly allocated to wait-and-see for LC. The primary outcome was recurrence of biliary events during a 2-year follow-up. The mean age in this group of patients was 60 years. Of the patients allocated to wait-and-see, $47 \%$ had recurrent biliary complications over 2 years when compared with $2 \%$ in patients who underwent an LC. In this group of patients, ES alone was an inadequate therapy compared with ES + LC because of high recurrent biliary complications. Young patients tended to develop recurrent biliary complications the most. These findings were compatible with the conclusions in our study for low-risk patients (younger than 70 years), for which we recommended ES followed by LC to prevent recurrent biliary complications. It should be noted that the biliary complication rate in the wait-and-see group (47\%) was significantly higher when compared with other similar trials. Several other trials ${ }^{28-30}$ have also suggested ES LC as treatment of choice in younger low-risk patients with choledocholithiasis.

Lai et al. ${ }^{31}$ looked at 140 patients (mean age 69 years) with intact gall-bladder, who underwent ES for clearance of stones in the bile duct. Of the 140 patients, 46 underwent elective LC soon after sphincterotomy and 94 did not. There was no statistically significant difference in recurrent complications between patients without gall-bladders vs. the patients with intact gall-bladders. Therefore, elective

(c) 2006 The Authors. This is the authors' version prior to publication in Alimentary Pharmacology \& Therapeutics 24(7):1059-1066, October 2006. The definitive version is available at www.blackwell-synergy.com (http://dx.doi.org/10.1111/j.1365-2036.2006.03103.x) Journal compilation (c) 2006 Blackwell Publishing. 
cholecystectomy after ES did not prevent the recurrent biliary complications in patients with cholelithiasis or nonfunctional or normal gall-bladder. Similar conclusions were drawn by Boytchev, ${ }^{32}$ in which late biliary complications after ES for choledocholithiasis in patients with gall-bladder in situ were rare $(2 \%$ per year) in patients with mean age of 78 years.

A recent study by Lau ${ }^{33}$ looking at patients with mean age of 71 years advocated ES + LC for choledocholithiasis. The authors stated that these patients should undergo ES + LC because of greater long-term morbidity and mortality in the ESalone group. However, closer look at this study reveals that the authors do not specifically mention immediate surgical mortality in patients undergoing cholecystectomy. Furthermore, the authors state that long-term mortality was higher in the ES-alone group. The long-term mortality rate estimates for ES-alone group vs. ES + LC group reveals that this is an estimation of 'all causes of death' rather than death caused by recurrent biliary complications. When one looks at long-term mortality from biliary complications alone among the two groups, the mortality rates are essentially the same.

Hammarstrom et al. ${ }^{34}$ retrospectively evaluated 184 patients (mean age $=81$ years) to see whether ES with common bile duct calculi and the gall-bladder in situ should be followed by routine cholecystectomy. These patients were followed for median duration of 69 months. Cholecystectomy was required in only 35 because of acute cholecystitis or biliary colic. The rest of patients who underwent ES alone were relatively asymptomatic. The findings in this study confirmed that endoscopic treatment alone in this group of patients was feasible treatment principle. Several other studies ${ }^{1,35-37}$ have further confirmed that octogenarians with common bile duct calculi do well with ES alone on long-term follow-up.

Targarona et al. ${ }^{38}$ carried out prospective trial of comparing ES + LC with that of ES for treatment of bile duct stones in patients with mean age of 80 years. Patients undergoing ES + LC had higher immediate morbidity when compared with the ES-alone group (23\% vs. $16 \%$ ). During mean follow-up of 17 months, the probability whether patients being free of biliary symptoms was higher in the ES + LC group than in the ES-alone group ( $85 \%$ and $61 \%$, respectively). These findings contradict the findings of our decision analysis and the previously mentioned studies. It is important to understand that our decision analysis is predictive model that utilizes data from multiple clinical trials rather than just one trial. The conclusions of our model are hence based upon data compiled from various studies and hence may not always agree with an individual study mentioned above. Furthermore, our conclusions recommending the ES-alone strategy in patients more than 80 years of age have been validated by sensitivity analysis that accounts for the marked variability in outcomes seen in the literature.

(c) 2006 The Authors. This is the authors' version prior to publication in Alimentary Pharmacology \& Therapeutics 24(7):1059-1066, October 2006. The definitive version is available at www.blackwell-synergy.com (http://dx.doi.org/10.1111/j.1365-2036.2006.03103.x) Journal compilation (c) 2006 Blackwell Publishing. 
The data analysis in our study indicates that for younger, relatively healthy patients, ES LC is the dominant strategy with an overall success rate of $90 \%$.

This result was further validated by sensitivity analysis. The mortality for the ES + LC group was also half that of the ES-alone group. ES alone is safe and effective procedure for most elderly patients with symptomatic cholelithiasis, including the extreme elderly, 80 years of age or older. When compared with other groups, elderly patients have much higher rate of conversion to an open cholecystectomy, more complications and mortality. Factors that account for these adverse outcomes include more comorbidities, especially coronary artery disease.

In conclusion, on the basis of these observations, we recommend that in younger patients (age $<70$ years) with choledocholithiasis, ES followed by elective LC should be encouraged before the development of biliary complications. Such an approach may serve to lower complications and mortality. More elderly patients (age >70 years) with multiple comorbidities are at greatly increased risk for surgical morbidity and mortality and should be considered for ES alone.

\section{ACKNOWLEDGEMENTS}

No external funding was received for this study.

\section{REFERENCES}

1. Hill J, Martin DF, Tweedle DE. Risks of leaving the gallbladder in situ after endoscopic sphincterotomy for bile duct stones. Br J Surg 1991; 78: 5547.

2. Davidson BR, Neoptolemos JP, Carr-Locke DL. Endoscopic sphincterotomy for common bile duct calculi in patients with gall bladder in situ considered unfit for surgery. Gut 1988; 29: 114-20.

3. Cotton PB, Geenen JE, Sherman S, et al. Endoscopic sphincterotomy for stones by experts is safe, even in younger patients with normal ducts. Ann Surg 1998; 227: 201-4.

4. Cotton PB, Vallon AG. British experience with duodenoscopic sphincterotomy for removal of bile duct stones. Br Surg 1981; 68: 373-5.

5. Escourrou J, Cordova JA, Lazorthes F, Frexinos J, Ribet A. Early and late complications after endoscopic sphincterotomy for biliary lithiasis with and without the gall bladder 'in situ'. Gut 1984; 25: 598-602. 
6. Tierney S, Lillemoe KD, Pitt HA. The current management of common duct stones. Adv Surg 1995; 28: 271-99.

7. Targarona EM, Pros I, Trias M. Treatment of choledocholithiasis in the high-risk patient. Med Clin 1992; 98: 69-73.

8. Winslet MC, Neoptolemos JP. The place of endoscopy in the management of gallstones. Baillieres Clinical Gastroenterology 1991; 5: 99-129.

9. Moreaux J. Traditional surgical management of common bile duct stones: a prospective study during 20-year experience. Am Surg 1995; 169: 22026.

10. Escarce JJ, Shea JA, Chen W, Qian Z, Schwartz JS. Outcomes of open cholecystectomy in the elderly: longitudinal analysis of 21,000 cases in the prelaparoscopic era. Surgery 1995; 117: 156- 64.

11. Neoptolemos JP, Carr-Locke DL, Fraser I, Fossard DP. The management of common bile duct calculi by endoscopic sphincterotomy in patients with gall-bladders in situ. Br J Surg 1984; 71: 69-71.

12. Freeman ML. Complications of endoscopic biliary sphincterotomy: a review. Endoscopy 1997; 29: 288-297.

13. Tulassay Z, Zagoni T, Kotrlik J. Complications of endoscopic biliary sphincterotomy. N Engl J Med 1997; 336: 963.

14. Clarke GA, Jacobson BC, Hammett RJ, Carr-Locke DL. The indications, utilization and safety of gastrointestinal endoscopy in an extremely elderly patient cohort. Endoscopy 2001; 33: 580-84.

15. Uhlich GA. Complications of diagnostic gastrointestinal endoscopy [comment]. Endoscopy 1991; 23: 245-6.

16. Benjamin SB. Overview of monitoring in endoscopy. Scand J Gastroenterol Suppl 1990; 179: 28-30.

17. Askew AR. Surgery for gallstones in the elderly. Aust Surg 1995; 65: 31215.

18. Behrman SW, Melvin WS, Babb ME, Johnson J, Ellison EC. Laparoscopic cholecystectomy in the geriatric population. Am Surg 1996; 62: 386-90.

(C) 2006 The Authors. This is the authors' version prior to publication in Alimentary Pharmacology \& Therapeutics 24(7):1059-1066, October 2006. The definitive version is available at www.blackwell-synergy.com (http://dx.doi.org/10.1111/j.1365-2036.2006.03103.x) Journal compilation @ 2006 Blackwell Publishing. 
19. Golden WE, Cleves MA, Johnston JC. Laparoscopic cholecystectomy in the geriatric population [see comment]. Am Geriatr Soc 1996; 44: 138083.

20. Majeski J. Laparoscopic cholecystectomy in geriatric patients. Am Surg 2004; 187: 747-50.

21. Hazzan D, Geron N, Golijanin D, Reissman P, Shiloni E. Laparoscopic cholecystectomy in octogenarians. Surg Endosc 2003; 17: 773-6.

22. Maxwell JG, Tyler BA, Maxwell BG, Brinker CC, Covington DL. Laparoscopic cholecystectomy in octogenarians. Am Surg 1998; 64: 82631.

23. Holbrook RF, Jacobson FL, Pezzuti RT, Howell DA. Biliary patency imaging after endoscopic retrograde sphincterotomy with gallbladder in situ. Clinical impact of nonvisualization. Arch Surg 1991; 126: 738-41.

24. Hutton SW, Sievert CE Jr, Vennes JA, Duane WC. Inhibition of gallstone formation by sphincterotomy in the prairie dog: reversal by atropine. Gastroenterology 1982; 82: 1308-13.

25. Hutton SW, Sievert CE Jr, Vennes JA, Shafer RB, Duane WC. Spontaneous passage of glass beads from the canine gallbladder: facilitation by sphincterotomy. Gastroenterology 1988; 94: 1031- 35.

26. Sugiyama M, Atomi Y. Longterm effects of endoscopic sphincterotomy on gall bladder motility. Gut 1996; 39: 856-9.

27. Boerma D, Rauws EA, Keulemans YC, et al. Wait-and-see policy or laparoscopic cholecystectomy after endoscopic sphincterotomy for bileduct stones: randomized trial. Lancet 2002; 360: 761-5.

28. Neoptolemos JP, Davidson BR, Shaw DE, Lloyd D, Carr-Locke DL, Fossard DP. Study of common bile duct exploration and endoscopic sphincterotomy in consecutive series of 438 patients. Br Surg 1987; 74: 916-21.

29. Miller BM, Kozarek RA, Ryan JA Jr, Ball TJ, Traverso LW. Surgical versus endoscopic management of common bile duct stones. Ann Surg 1988; 207: 135- 41 .

30. Yi SY. Recurrence of biliary symptoms after endoscopic sphincterotomy for choledocholithiasis in patients with gall bladder stones. Gastroenterol

(C) 2006 The Authors. This is the authors' version prior to publication in Alimentary Pharmacology \& Therapeutics 24(7):1059-1066, October 2006. The definitive version is available at www.blackwell-synergy.com (http://dx.doi.org/10.1111/j.1365-2036.2006.03103.x) Journal compilation (c) 2006 Blackwell Publishing. 
Hepatol 2000; 15: 661-4.

31. Lai KH, Lin LF, Lo GH, et al. Does cholecystectomy after endoscopic sphincterotomy prevent the recurrence of biliary complications? Gastrointest Endosc 1999; 49: 483-7.

32. Boytchev I, Pelletier G, Prat F, Choury AD, Fritsch J, Buffet C. Late biliary complications after endoscopic sphincterotomy for common bile duct stones in patients older than 65 years of age with gallbladder in situ. Gastroenterol Clin Biol 2000; 24: 995-1000.

33. Lau JY, Leow CK, Fung TM, et al. Cholecystectomy or gallbladder in situ after endoscopic sphincterotomy and bile duct stone removal in Chinese patients.

34. Gastroenterology 2006; 130: 96-103. Hammarstrom LE, Holmin T, Stridbeck $\mathrm{H}$. Endoscopic treatment of bile duct calculi in patients with gallbladder in situ: long-term outcome and factors. Scand Gastroenterol 1996; 31: 294-301.

35. Schreurs WH, Vles WJ, Stuifbergen WH, Oostvogel HJ. Endoscopic management of common bile duct stones leaving the gallbladder in situ. cohort study with long-term follow-up. Dig Surg 2004; 21 : 60-4, discussion 65.

36. Himal HS. Role of endoscopic sphincterotomy alone in patients with choledocholithiasis and cholelithiasis. Can Surg 1996; 39: 225-8.

37. Sugiyama M, Suzuki Y, Abe N, Masaki T, Mori T, Atomi Y. Endoscopic retreatment of recurrent choledocholithiasis after sphincterotomy. Gut 2004; 53: 1856-9.

38. Targarona EM, Ayuso RM, Bordas JM, et al. Randomised trial of endoscopic sphincterotomy with gallbladder left in situ versus open surgery for common bileduct calculi in high-risk patients. Lancet 1996; 347: 926-9.

39. Shamiyeh A, Wayand W. Laparoscopic cholecystectomy: early and late complications and their treatment. Langenbecks Arch Surg 2004; 389: $164-71$.

40. Soper NJ, Flye MW, Brunt LM, et al. Diagnosis and management of biliary complications of laparoscopic cholecys tectomy. Am Surg 1993; 165: 6639.

(c) 2006 The Authors. This is the authors' version prior to publication in Alimentary Pharmacology \& Therapeutics 24(7):1059-1066, October 2006. The definitive version is available at www.blackwell-synergy.com (http://dx.doi.org/10.1111/j.1365-2036.2006.03103.x) Journal compilation (c) 2006 Blackwell Publishing. 
41. Kwon SK, Lee BS, Kim NJ, et al. Is cholecystectomy necessary after ERCP for bile duct stones in patients with gallbladder in situ? Korean Intern Med 2001; 16: 254-9.

42. Trias M, Targarona EM, Ros E, et al. Prospective evaluation of a minimally invasive approach for treatment of bile-duct calculi in the highrisk patient. Surg Endosc 1997; 11: 632-5.

43. Bingener J, Richards ML, Schwesinger WH, Strodel WE, Sirinek KR. Laparoscopic cholecystectomy for elderly patients: gold standard for golden years? Arch Surg 2003; 138: 531-5 (discussion 535-6).

44. Pessaux P, Regenet N, Tuech JJ, Rouge C, Bergamaschi R, Arnaud JP. Laparoscopic versus open cholecystectomy: prospective comparative study in the elderly with acute cholecystitis. Surg Laparosc Endosc Percutan Tech 2001; 11: 252-5.

45. Pessaux P, Tuech JJ, Derouet N, Rouge C, Regenet N, Arnaud JP. Laparoscopic cholecystectomy in the elderly: prospective study. Surg Endosc 2000; 14: 1067-9.

46. Pessaux P, Tuech JJ, Duplessis R, Seicean R, Arnaud JP. Laparoscopic cholecystectomy after age 75. Chirurgie 1999; 124: 419-22.

47. Kaw M, Al-Antably Y, Kaw P. Management of gallstone pancreatitis: cholecystectomy or ERCP and endoscopic sphincterotomy. Gastrointest Endosc 2002; 56: 61-5.

48. Tambyraja AL, Kumar S, Nixon SJ. Outcome of laparoscopic cholecystectomy in patients 80 years and older. World J Surg 2004; 28 : 745-8.

49. Brunt LM, Quasebarth MA, Dunnegan DL, Soper NJ. Outcomes analysis of laparoscopic cholecystectomy in the extremely elderly. Surg Endosc 2001.

50. Pereira-Lima JC, Jakobs R, Winter UH, et al. Long-term results (7 to 10 years) of endoscopic papillotomy for choledocholithiasis. Multivariate analysis of prognostic factors for the recurrence of biliary symptoms. Gastrointest Endosc 1998; 48: 457-64.

51. Pereira-Lima JC, Rynkowski CB, Rhoden EL. Endoscopic treatment of choledocholithiasis in the era of laparoscopic cholecystectomy: prospective analysis of 386 patients. Hepatogastroenterology 2001; 48:

(c) 2006 The Authors. This is the authors' version prior to publication in Alimentary Pharmacology \& Therapeutics 24(7):1059-1066, October 2006. The definitive version is available at www.blackwell-synergy.com (http://dx.doi.org/10.1111/j.1365-2036.2006.03103.x) Journal compilation (c) 2006 Blackwell Publishing. 
$1271-4$.

52. Costamagna G, Tringali A, Shah SK, Mutignani M, Zuccala G, Perri V. Long-term follow-up of patients after endoscopic sphincterotomy for choledocholithiasis, and risk factors for recurrence. Endoscopy 2002; 34: 273-9.

53. Keulemans YC, Rauws EA, Huibregtse K, Gouma DJ. Current management of the gallbladder after endoscopic sphincterotomy for common bile duct stones. Gastrointest Endosc 1997; 46: 514-9.

54. Ikeda S, Tanaka M, Matsumoto S, Yoshimoto H, Itoh H. Endoscopic sphincterotomy: long-term results in 408 patients with complete follow-up. Endoscopy 1988; 20: 13-17.

55. Lamont DD, Passi RB. Fate of the gallbladder with cholelithiasis after endoscopic sphincterotomy for choledocholithiasis. Can Surg 1989; 32: $15-18$.

\section{TABLES \& FIGURES}

\section{TABLE 1}

Decision analysis baseline values for endoscopic sphincterotomy (ES) + laparoscopic cholecystectomy (LC) group.

\begin{tabular}{|c|c|c|c|c|}
\hline Age (years) & $\begin{array}{l}\text { Immediate } \\
\text { complications } \\
(\%)\end{array}$ & $\begin{array}{l}\text { Immediate } \\
\text { post-surgical } \\
\text { mortality (\%) }\end{array}$ & $\begin{array}{l}\text { Long-term } \\
\text { complications (\%) }\end{array}$ & $\begin{array}{l}\text { Long-term } \\
\text { mortality (\%) }\end{array}$ \\
\hline \multicolumn{5}{|c|}{ Complications/mortality in ES + LC group } \\
\hline $\begin{array}{l}<70^{27,30,39,40} 4(2-7) \\
70-79^{31,39-46} \\
>80^{21,31,39,40,43-49}\end{array}$ & $\begin{array}{l}0.2 \\
11(10-14) \\
17(16-19)\end{array}$ & $\begin{array}{l}2.2 \\
4.25\end{array}$ & $\begin{array}{l}-8) \\
5.8(0.5-8) \\
5.8(0.5-8)\end{array}$ & $\begin{array}{l}0.7 \\
0.7\end{array}$ \\
\hline
\end{tabular}

\section{TABLE 2}

(C) 2006 The Authors. This is the authors' version prior to publication in Alimentary Pharmacology \& Therapeutics 24(7):1059-1066, October 2006. The definitive version is available at www.blackwell-synergy.com (http://dx.doi.org/10.1111/j.1365-2036.2006.03103.x) Journal compilation (c) 2006 Blackwell Publishing. 
Decision analysis baseline values for endoscopic sphincterotomy (ES)-alone group.

\begin{tabular}{lll}
\hline Age (years) & $\begin{array}{l}\text { Long-term } \\
\text { complications }(\%)\end{array}$ & $\begin{array}{l}\text { Long-term } \\
\text { mortality (\%) }\end{array}$ \\
& \\
\hline Complications/mortality in ES-alone group & \\
& & \\
$<70^{27,30,34,41,47,50-54}$ & $15(5-24)$ & 0.7 \\
$70-79^{7,31-35,38,41,42,47,50-55}$ & $15(11-20)$ & 0.7 \\
$>80^{7,31,32,34,45,38,41,47,50-54}$ & $15(6-25)$ & 0.7 \\
\hline
\end{tabular}

\section{TABLE 3}

Decision model analysis results

\begin{tabular}{lllll}
\hline $\begin{array}{l}\text { Age } \\
\text { (years) }\end{array}$ & $\begin{array}{l}\text { ES } \\
\text { success }\end{array}$ & $\begin{array}{l}\text { ES mortality } \\
(\%)\end{array}$ & $\begin{array}{l}\text { ES + LC } \\
\text { success }\end{array}$ & $\begin{array}{l}\text { ES + LC } \\
\text { mortality (\%) }\end{array}$ \\
\hline$<70$ & 85 & 0.1 & 90 & 0.05 \\
$70-79$ & 85 & 0.1 & 83 & 0.34 \\
$80+$ & 86 & 0.1 & 78 & 0.76 \\
\hline
\end{tabular}

\section{FIGURE 1}

Decision model tree used in our analysis. 


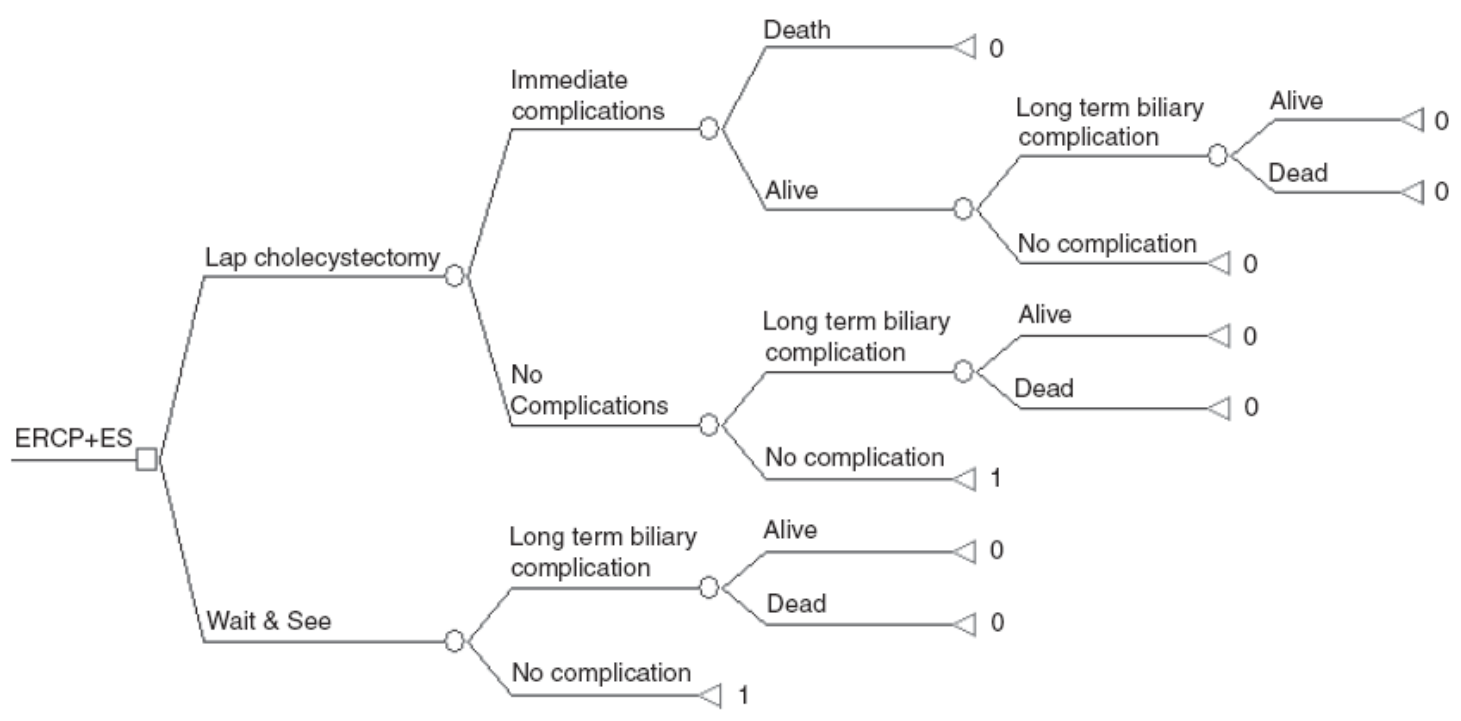

FIGURE 2

Results of sensitivity analysis showing a threshold surgical complication rate of $9.8 \%$, above which ES was the dominant strategy.

(C) 2006 The Authors. This is the authors' version prior to publication in Alimentary Pharmacology \& Therapeutics 24(7):1059-1066, October 2006. The definitive version is available at www.blackwell-synergy.com (http://dx.doi.org/10.1111/j.1365-2036.2006.03103.x) Journal compilation @ 2006 Blackwell Publishing. 


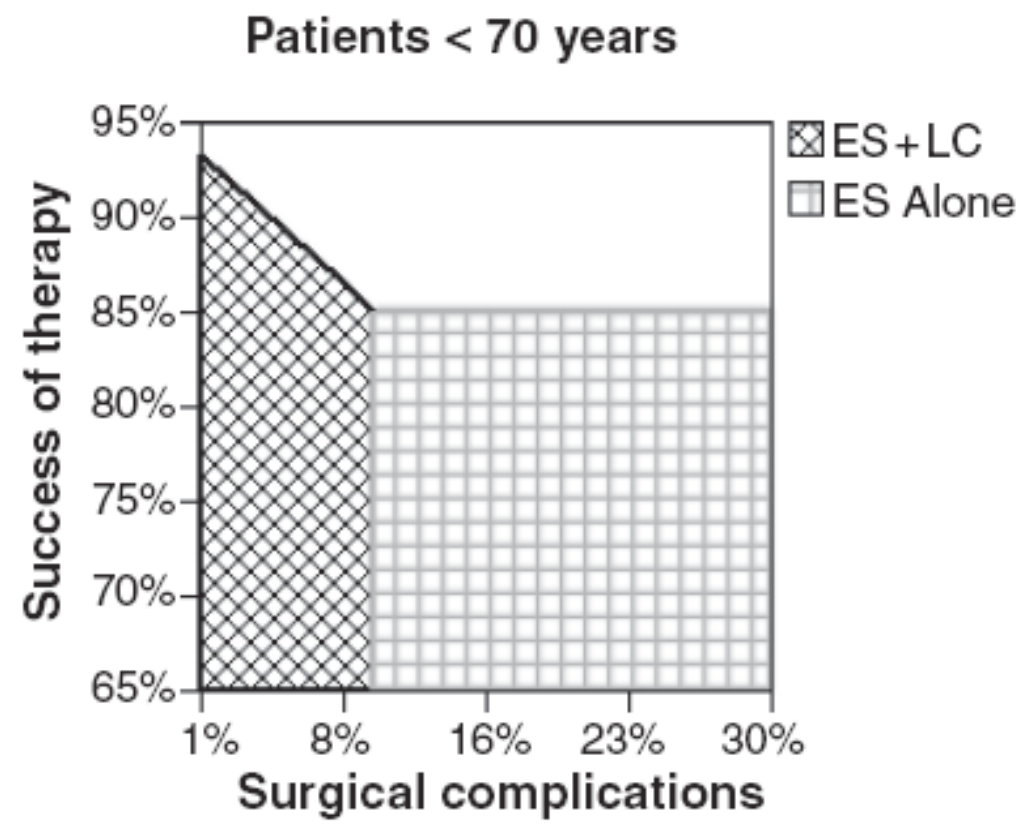

FIGURE 3

Results of sensitivity analysis showing a threshold surgical complication rate of $10 \%$, above which ES was the dominant strategy.

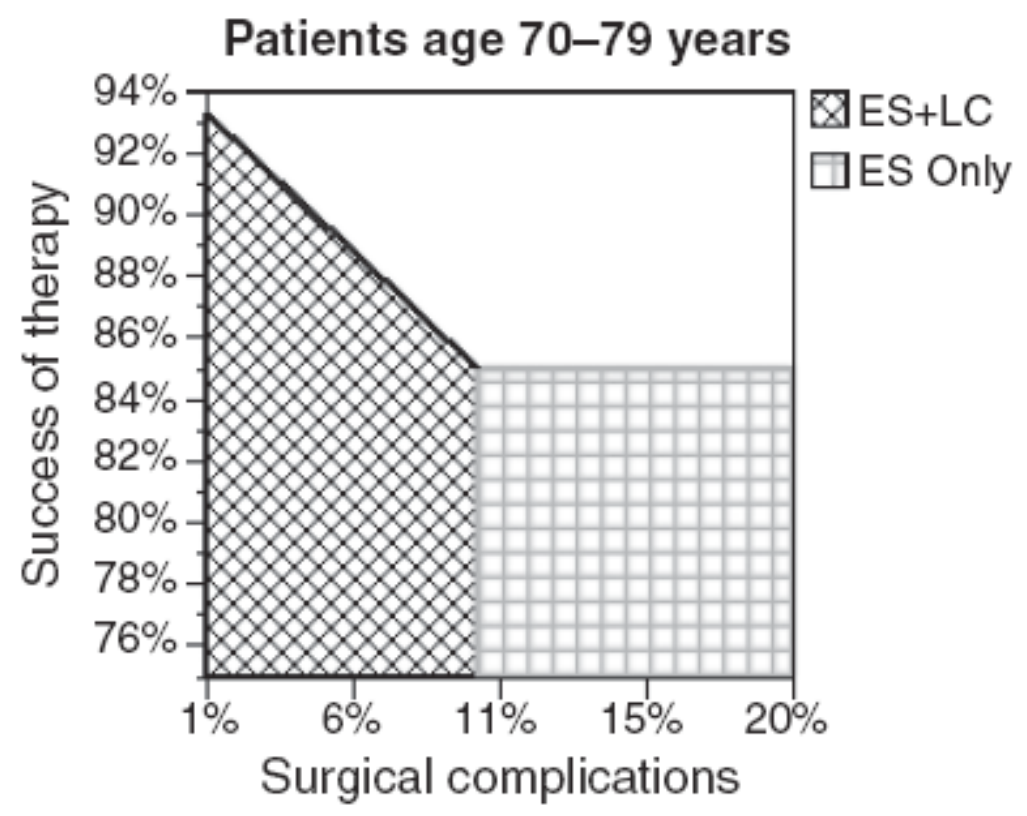

(c) 2006 The Authors. This is the authors' version prior to publication in Alimentary Pharmacology \& Therapeutics 24(7):1059-1066, October 2006. The definitive version is available at www.blackwell-synergy.com (http://dx.doi.org/10.1111/j.1365-2036.2006.03103.x) Journal compilation @ 2006 Blackwell Publishing. 